\title{
Effect of Biodiesel on Polyamide-6-Based Polymers
}

\author{
Jianwei Zhao, Pankaj K. Mallick (i) \\ Department of Mechanical Engineering, University of Michigan-Dearborn, Dearborn, Michigan, 48128
}

\begin{abstract}
Biodiesel is considered one of the best alternative fuel sources in the transportation industry, but it has shown aggressive characteristics on materials that are used in fuel storage and delivery systems in vehicles. In this study, the effect of biodiesel (B100) on the properties of two polyamide6-based semicrystalline polymers was studied and compared with that of diesel and a 20/80 blend of biodiesel and diesel (B20). Experiments were conducted using room temperature immersion tests in the three fuels for $720 \mathrm{~h}$ followed by postimmersion thermal and mechanical tests. In all three fuels, the polymers exhibited non-Fickian weight increase during immersion and did not achieve equilibrium level of absorption in $720 \mathrm{~h}$. The glass transition temperature $\left(T_{g}\right)$, yield and tensile strengths, storage modulus, and peak $\tan \delta$ decreased after immersion, while the degree of crystallinity and loss modulus increased. Fourier transform infrared spectroscopy study showed that no chemical changes occurred due to immersion. It is concluded that all three fuels absorbed into the polymers acted as plasticizers which caused the observed changes in the properties of the two polymers investigated in this research. POLYM. ENG. SCI., 59:1445-1454, 2019. ( 2019 Society of Plastics Engineers
\end{abstract}

\section{INTRODUCTION}

Polymers are used in many fuel container and fuel delivery applications where they are exposed to or immersed in fuels that can cause degradation in their physical and mechanical properties. The degradation may take place immediately or over a period. Richaud et al. [1] divided the effect of polymer-fuel interactions into two main categories: physical and chemical, both occurring as a result of diffusion and absorption of the fuel into the polymer. The physical interaction may cause stress cracking on the polymer surface, alter physical and mechanical properties or extract performance-enhancing additives used in the polymer, but no chemical modifications of the polymer molecules. The chemical interaction, on the other hand, may cause oxidation or hydrolysis of the polymer molecules due to the reaction with functional groups, such as esters and amides, that may be present in the fuel.

In recent years, biodiesel has emerged as one of the primary alternative fuels for diesel engines. Biodiesel comprises of fatty acid methyl esters (FAMEs) derived from vegetable oils, animal fats, or recycled greases [2-5]. It is used either as $100 \%$ FAME, often designated as B100, or in lower volumetric concentrations in which it is blended with diesel, such as a B20 blend in which $20 \%$ biodiesel is blended with $80 \%$ diesel. Biodiesel has several advantages over diesel, such as high combustion, lower carbon dioxide emission, sustainability, biodegradability, and eco-friendliness. Because of these advantages, it is considered an excellent fuel for both city and highway driving of automobiles and other vehicles. However,

Correspondence to: P. K. Mallick; e-mail: pkm@umich.edu DOI 10.1002/pen.25131

Published online in Wiley Online Library (wileyonlinelibrary.com).

(C) 2019 Society of Plastics Engineers compared to traditional diesel, biodiesel shows much more aggressiveness on fuel storage and delivery systems. For example, it can be highly corrosive on metals used in vehicle fuel lines [6], and when exposed to air during long-term storage, biodiesel tends to oxidize which increases its acid content and in turn, increases the corrosion rate. Similarly, traditional elastomers used in fuel line hoses, gaskets, and O-rings are also shown to degrade by swelling and other physical changes on long-term exposure to biodiesel.

Majority of the studies on the effect of biodiesel on polymers have been conducted with elastomers, such as nitrile rubbers, fluoroelastomers, and silicone rubber that are used in today's diesel engines [7-13]. The changes in the physical and mechanical properties of these elastomers after immersion in biodiesel were attributed to chemical changes, such as the generation of functional groups, additional crosslinking, and chain scission. There are fewer reported studies in which the effect of biodiesel on thermoplastic polymers was considered. Richaud et al. [14] conducted immersion experiments to measure absorption of rapeseed and soy biodiesels in pipe-grade polyethylene films and reported that the amount of absorption increased with increasing immersion time, but reached an equilibrium level of $4.7 \%$ in approximately $139 \mathrm{~h}$ at $23^{\circ} \mathrm{C}$. The equilibrium concentration increased with increasing temperature. Böhning et al. [15-17] investigated the influence of biodiesel and diesel on tensile and impact properties of several different high-density polyethylene (HDPE) grades. They observed significant decrease in modulus, but increase in both tensile failure strain and impact strength, all of which were attributed to plasticization effect of biodiesel absorption in HDPE. Lutz and Mata-Segreda [18] reported the immersion experiment results of a highly plasticized polyvinyl chloride (PVC) and two different high-impact polystyrenes (HIPS) in diesel and palm ethyl biodiesel at $20^{\circ} \mathrm{C}$. At the end of 3 months, PVC transformed from a flexible material to a rigid brittle material due to the loss of plasticizer from it. The diffusion of biodiesel in HIPS depended on the ratio of benzene rings to $\mathrm{CH}=\mathrm{CH}$ units in the polymer molecules. Ullah [19] examined the effect of B20 blend on the impact strength of a polyoxymethylene (POM) copolymer. The impact strength decreased by $37.5 \%$, which was attributed to the presence of surface cracks generated after $800 \mathrm{~h}$ of immersion. Baleno et al. [20] considered the effect of a B30 blend on the properties of unfilled, glass fiber reinforced and carbon fiber reinforced polyphthalamide. Even after 5,000-h immersion at $90^{\circ} \mathrm{C}$, they did not observe any changes in weight, tensile, flexural, and impact properties of these materials. Gomez-Mares et al. [21] conducted immersion tests in diesel and B30 blend for up to $1,008 \mathrm{~h}$ at $120^{\circ} \mathrm{C}$ using unreinforced and glass fiber reinforced POM, polyphthalamide, and polyphenylene sulfide and did not observe much changes in their tensile properties. In another study, Baena et al. [22] evaluated the stability of HDPE, POM, and polyamide-66 (PA-66) in palm biodiesel and its blends. After immersion for 14 to $18 \mathrm{~h}$ at $55^{\circ} \mathrm{C}$, HDPE and POM did not show any significant changes in mechanical properties, but PA-66 had a significant decrease in tensile strength. However, Fourier transform infrared spectroscopy (FTIR) study showed that there were no appreciable changes in the chemical structures of these polymers. The changes in mechanical properties were explained as mainly due to physical absorption of the fuels into the polymers. 
The objective of the current research is to determine the effects of biodiesel on the properties of two polyamide-6-based polymers that may find applications in fuel tanks, fuel flow lines, and fuel distribution systems in road vehicles. Currently, the polymer used for gasoline fuel tanks is HDPE. However, since HDPE has a relatively high permeability for gasoline, it is either layered with ethylene vinyl alcohol or crosslinked. Polyamide- 6 has a significantly lower gasoline permeability than HDPE, and therefore, can be used in monolayer. It also has a much higher modulus and strength, and therefore, can be designed with thinner walls. As a result, polyamide fuel tanks can be lighter, and has the potential of being cost competitive with HDPE fuel tanks. As mentioned before, several studies have addressed the effect of biodiesel on HDPE; similar studies on polyamide- 6 is lacking. If polyamide- 6 is selected for use in biodiesel fuel tanks or other biodiesel storage applications, the effect of biodiesel on polyamide- 6 will be of interest.

\section{EXPERIMENTAL}

Fuels

Three different fuels were used in this research: $100 \%$ diesel, $100 \%$ biodiesel (B100), and a volumetric blend of $20 \%$ biodiesel and $80 \%$ diesel (B20). All the fuels were purchased from Iowa Central Fuel Testing Laboratory, Fort Dodge, IA. The biodiesel is reported to be soybean based with an ester content of $97.6 \%$ and a moisture content of $0.011 \%$. As shown in Fig. 1, the chemistry of biodiesel is very similar to that of diesel. Both contain hydrocarbon molecules, typically 16 carbon atoms long, and except at the ends, two hydrogen atoms are attached to each carbon atom. The biodiesel molecule contains a methyl ester group or $\mathrm{COOCH}_{3}$ group at one of its ends instead of a methyl group or $\mathrm{CH}_{3}$ group as in diesel.

\section{Polymers}

Two commercially available polyamide-6-based polymers were selected for the immersion tests: Capron 8202, a homopolymer [23] and Capron 8351, a graft copolymer [24]. Both are semicrystalline polymers and are known to have excellent chemical resistance to oils and hydrocarbons, and are candidates for fuel storage and delivery systems. The copolymer has a higher impact resistance than the homopolymer. They were supplied by the BASF Corporation in the form of extruded black-pigmented sheets.

\section{Specimen Size}

Rectangular specimens cut from the extruded sheets were used in all experiments. The average thickness of Capron 8202 was $1.62 \mathrm{~mm}$ and that of Capron 8351 was $1.55 \mathrm{~mm}$. Two different specimen sizes were used: $7 \times 25 \mathrm{~mm}^{2}$ for weight measurements and DMA tests, and $14 \times 50 \mathrm{~mm}^{2}$ for tension tests.

\section{Specimen Drying}

Before the immersion experiments, the specimens were dried in an air-circulating oven at $85^{\circ} \mathrm{C}$ for $96 \mathrm{~h}$. The moisture content in the sheets was not directly measured; however, the specimens were dried at $85^{\circ} \mathrm{C}$ for various lengths of time to remove the absorbed moisture and their weight loss was measured. Drying was continued until the weight loss became stable. It was observed that the weights reduced sharply within the first $24 \mathrm{~h}$ of drying, and tended to become stable at around $2.58 \%$ for Capron 8202 and $1.96 \%$ for Capron 8351 after $96 \mathrm{~h}$ of drying. Another parameter used in verifying the drying time effect was the glass transition temperature, $T_{g}$, which was measured using Dynamic mechanical analysis (DMA). For both polymers, $T_{g}$ increased from $25^{\circ} \mathrm{C}$ to $65^{\circ} \mathrm{C}$ after $24 \mathrm{~h}$ of drying. It then increased slowly and tended to stabilize at $70.77^{\circ} \mathrm{C}$ for Capron 8202 and $70.20^{\circ} \mathrm{C}$ for Capron 8351 . The increase in $T_{g}$ can be attributed to desorption of moisture in the polymers. Following these two experiments, all specimens were ovendried at $85^{\circ} \mathrm{C}$ for $96 \mathrm{~h}$ before conducting the immersion experiments.

\section{Immersion Experiments}

The dried specimens of Capron 8202 and 8351 were immersed in sealed glass containers filled with diesel, B20 and B100 fluids at $25^{\circ} \mathrm{C}$ for up to $720 \mathrm{~h}$. Specimens were taken out from the container at regular time intervals to measure their weight change. Several dried specimens of Capron 8202 and 8351 were immersed under stress in all three fluids at $25^{\circ} \mathrm{C}$ for $720 \mathrm{~h}$. In the stressed immersion tests, specimens were held in a bent configuration in a $37 \mathrm{~mm}$ wide C-channel, as shown in Fig. 2. Specimens were removed from the containers and released from the C-channel after $720 \mathrm{~h}$.

It is assumed that the specimen inserted in the C-channel is part of a circle as shown in Fig. 2. Assuming an elastic deformation, the tensile strain on the top outside surface of the stressed specimen is $\varepsilon=\frac{h}{2 R}$, where $h$ is the specimen thickness and $R$ is the radius of curvature, which was calculated to be equal to be $19.13 \mathrm{~mm}$. Since the thicknesses of Capron 8202 and Capron 8351 specimens were 1.62 and $1.55 \mathrm{~mm}$, respectively, the corresponding tensile strains were $4.23 \%$ and $4.05 \%$. The estimated tensile yield strains from the manufacturer's published data are $2.8 \%$ and $3.3 \%$, respectively. Thus, the tensile strains in the stressed specimens were slightly higher than the yield strains of the polymers. The reported failure strains of both polymers is $50 \%$ or higher $[23,24]$.

\section{Postimmersion Experiments}

After immersion, specimens were tested to determine the physical and chemical changes that may have occurred due to immersion. The postimmersion experiments included weight measurements, tensile tests, DMA, differential scanning calorimetry (DSC), and FTIR.

The specimen weights before and after immersion were measured using an electronic analytical balance, Denver Instrument SI-234, which has a readability of $0.0001 \mathrm{~g}$. Tensile tests were

$$
\text { Typical diesel molecule }
$$

FIG. 1. Typical biodiesel and diesel molecules. [Color figure can be viewed at wileyonlinelibrary.com] 

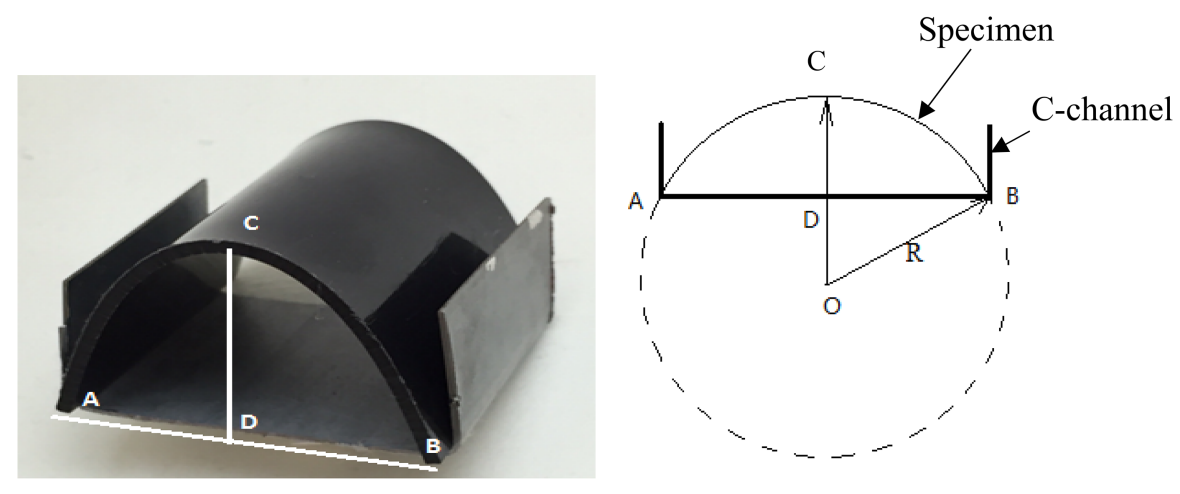

FIG. 2. Specimen inserted in a C-channel and the assumed specimen geometry in stressed immersion test. [Color figure can be viewed at wileyonlinelibrary.com]

conducted using an INSTRON 4469 materials testing machine. Straight-sided rectangular specimens, $50 \mathrm{~mm}$ in length and $14 \mathrm{~mm}$ in width, were used. The tests were conducted at a crosshead speed of $2.5 \mathrm{~mm} / \mathrm{min}$. The tensile strength was calculated using the maximum load and the yield strength was calculated using the stress at the end of the elastic part of the stress-strain diagram.

Dynamic mechanical properties were measured using a TTDMA (Model No. TRITON T1014231). The specimen was held in a three-point beam bending mode and a loading frequency of $1 \mathrm{~Hz}$ was applied at the midlength of the specimen. The temperature ramp rate was $2^{\circ} \mathrm{C} / \mathrm{min}$ and the end temperature was set at $110^{\circ} \mathrm{C}$.

The degree of crystallinity $C$ was measured using a DSC (TA Instruments SDT Q600). It was determined by analyzing the DSC thermogram during the heating cycle and was calculated using the following equation.

$$
C=\Delta H_{f}\left(T_{m}\right) / \Delta H_{f}^{0}\left(T_{m}^{0}\right)
$$

where $\Delta H_{f}\left(T_{m}\right)$ is the enthalpy of fusion measured at the melting temperature $T_{m}$ and $\Delta H_{f}^{0}\left(T_{m}^{0}\right)$ is the enthalpy of fusion of the

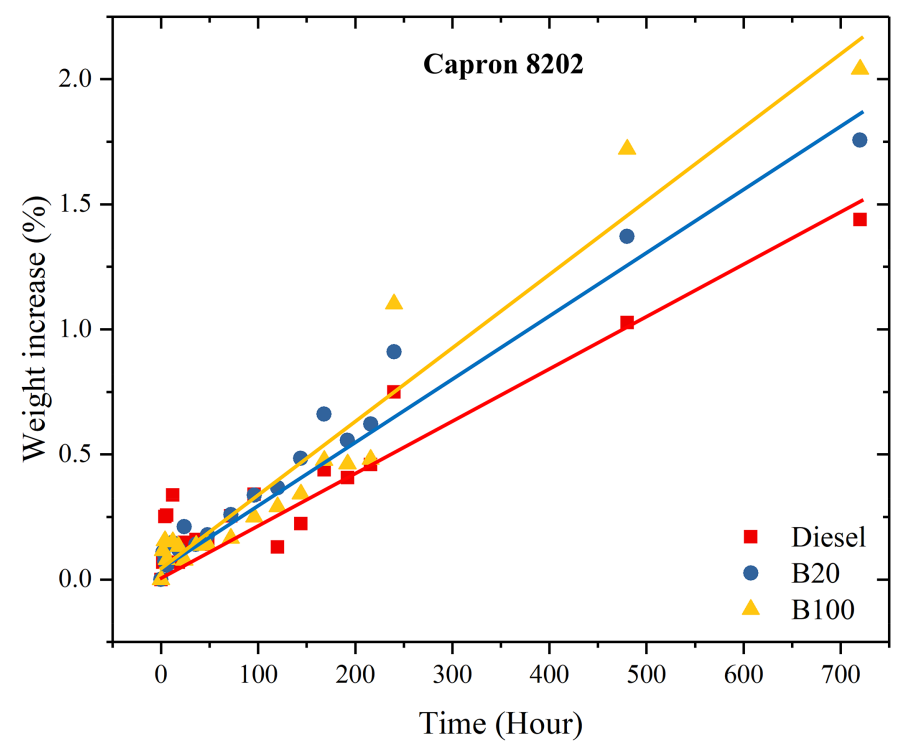

FIG. 3. Percentage weight increase of Capron 8202 in diesel, B20, and B100 as a function of time. [Color figure can be viewed at wileyonlinelibrary.com] totally crystalline polymer measured at the equilibrium melting temperature $T_{m}^{o}$. For polyamide- $6, \Delta H_{f}^{0}\left(T_{m}^{0}\right)=230.1 \mathrm{~J} / \mathrm{g}$, which was used in the degree of crystallinity calculations of both Capron 8202 and Capron 8351 . The heating rate was $8^{\circ} \mathrm{C} / \mathrm{min}$, starting from $25^{\circ} \mathrm{C}$ and ending at $250^{\circ} \mathrm{C}$. The heating thermogram of Capron 8202 exhibited one melting peak at its crystalline melting temperature. The heating thermogram of Capron 8351 exhibited two melting peaks. The larger peak is the primary peak which occurs at the crystalline melting temperature of polyamide- 6 , whereas the smaller peak is the secondary peak that occurs at the melting temperature of the rubbery phase present in this polymer.

\section{RESULTS}

\section{Physical Effects}

Figures 3 and 4 show percentage weight increase of dry Capron 8202 and 8351 specimens after immersion at $25^{\circ} \mathrm{C}$ as a function of $t$, where $t$ is the immersion time in hours. None of the three fuels reached the equilibrium level of absorption in $720 \mathrm{~h}$ of immersion. Among the three fuels considered, the highest absorption was observed in B100 and the lowest in diesel. To determine

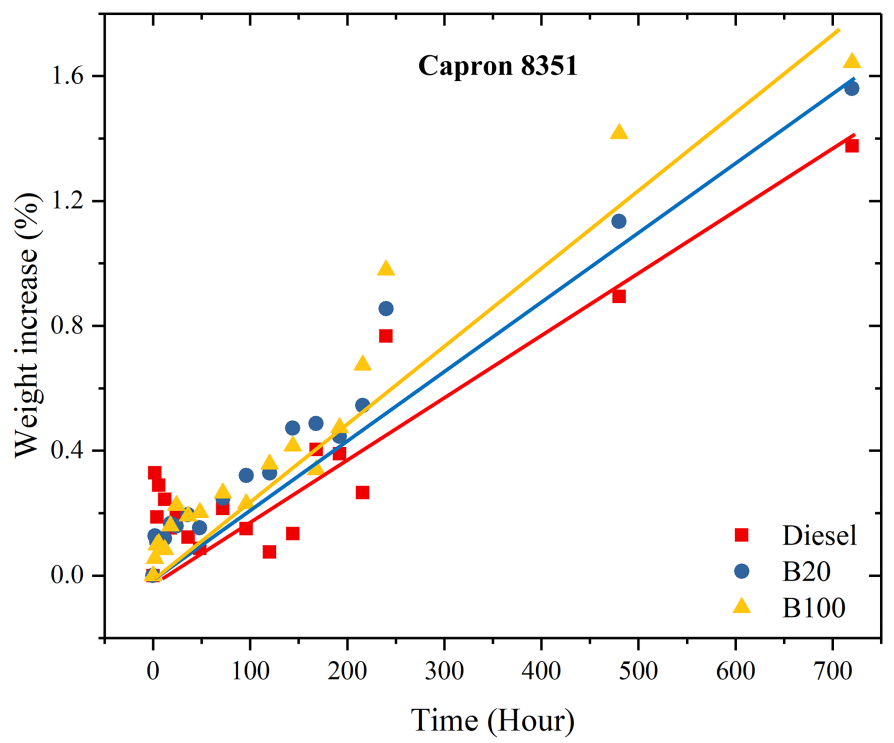

FIG. 4. Percentage weight increase of Capron 8351 in diesel, B20, and B100 as a function of time. [Color figure can be viewed at wileyonlinelibrary.com] 
TABLE 1 . Weight increase after $720 \mathrm{~h}$ of immersion at $25^{\circ} \mathrm{C}$.

\begin{tabular}{|c|c|c|c|c|}
\hline \multirow[b]{3}{*}{ Fuel } & \multicolumn{4}{|c|}{ Percentage weight increase after $720 \mathrm{~h}$ of immersion ${ }^{\mathrm{a}}$} \\
\hline & \multicolumn{2}{|c|}{ Unstressed } & \multicolumn{2}{|l|}{ Stressed } \\
\hline & 8202 & 8351 & 8202 & 8351 \\
\hline Diesel & 1.439 & 1.377 & 1.560 & 1.312 \\
\hline B20 & 1.756 & 1.560 & 1.866 & 1.511 \\
\hline B100 & 2.041 & 1.643 & 2.231 & 1.753 \\
\hline
\end{tabular}

average of five specimens for each condition.

if the fuel absorption followed the Fickian diffusion model [25], the weight increase data were examined as a function of $t^{0.5}$ and it was observed that it follows a sigmoidal relationship with $t^{0.5}$ instead of a linear relationship, which indicates a non-Fickian diffusion characteristic. It is interesting to note that biodiesel absorption in both Capron 8202 and 8351 after 720 h was significantly lower compared to HDPE for which the equilibrium level was $4.7 \%$, achieved in approximately $139 \mathrm{~h}$ at $23^{\circ} \mathrm{C}$ [14].

Table 1 summarizes the weight increases of both Capron 8202 and 8351 specimens after $720 \mathrm{~h}$ of immersion in diesel, B20, and
B100 fuels under unstressed and stressed immersion conditions. It can be observed in Table 1 that for both Capron 8202 and 8351 specimens in $25^{\circ} \mathrm{C}$ immersion tests, the highest weight increase under both unstressed and stressed conditions was in B100, followed by B20 and diesel. Compared to Capron 8202 specimens, the absorption of all three fuels was lower in Capron 8351 specimens. The weight of the stressed Capron 8202 specimens after 720-h immersion was higher than the unstressed Capron 8202 specimens. For the stressed Capron 8351 specimens, the weight increase was higher only in B100.

The absorption of all three fuels was also manifested in thickness changes which increased with increasing immersion time and ranged up to $1.85 \%$. Visual observation as well as scanning electron micrographs of the surfaces of immersed specimens did not reveal any anomalous surface characteristics, such as discoloration, voids, or fine cracks.

\section{Yield and Tensile Strengths}

The yield and tensile strengths of Capron 8202 and 8351 specimens immersed in diesel, B20, and B100 under different immersion conditions are listed in Table 2. For comparison, tensile strength data of both Capron 8202 and 8351 specimens before

TABLE 2. Yield and tensile strengths of Capron 8202 and 8351 before and after 720 -h immersion at $25^{\circ} \mathrm{C}^{\mathrm{a}}$.

\begin{tabular}{|c|c|c|c|c|c|}
\hline \multirow[b]{2}{*}{ Immersion condition } & & \multicolumn{2}{|l|}{ Capron 8202} & \multicolumn{2}{|l|}{ Capron 8351} \\
\hline & & Yield strength (MPa) & Tensile strength (MPa) & Yield strength (MPa) & Tensile strength (MPa) \\
\hline Before immersion & & 62.7 & 67.3 & 40.7 & 44.2 \\
\hline \multirow[t]{3}{*}{ After 720 -h immersion at $25^{\circ} \mathrm{C}$} & DIESEL & 59.7 & 64.5 & 38.6 & 42.5 \\
\hline & B20 & 58.2 & 65.1 & 36.4 & 37.8 \\
\hline & B100 & 58.4 & 64.5 & 38.5 & 43.1 \\
\hline \multirow[t]{3}{*}{ After 720 -h stressed immersion at $25^{\circ} \mathrm{C}$} & DIESEL & 56.0 & 64.7 & 34.8 & 37.7 \\
\hline & B20 & 54.5 & 63.3 & 32.7 & 37.4 \\
\hline & B100 & 51.5 & 61.0 & 34.0 & 39.1 \\
\hline
\end{tabular}

${ }^{\mathrm{a}}$ Average of three specimens for each condition.
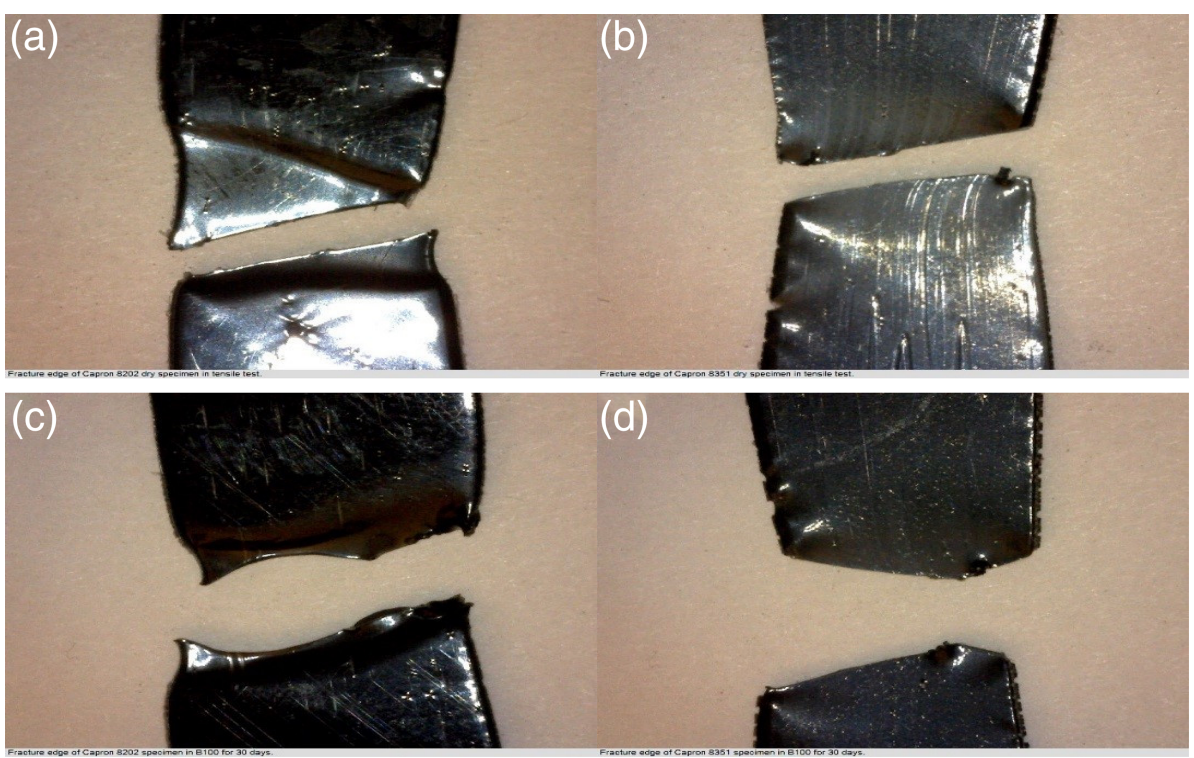

FIG. 5. Tensile failure modes of specimens before and after immersion: (a) Capron 8202 before immersion, (b) Capron 8351 before immersion, (c) Capron 8202 after 720-h immersion in B100, and (d) Capron 8351 after 720-h immersion in B100. [Color figure can be viewed at wileyonlinelibrary.com] 
TABLE 3. $T_{g}$, peak tan $\delta$, storage modulus, and loss modulus of Capron 8202 and 8351 at $25^{\circ} \mathrm{C}$.

\begin{tabular}{|c|c|c|c|c|c|c|c|}
\hline Material & Time of immersion (h) & Condition & & $T_{g}\left({ }^{\circ} \mathrm{C}\right)$ & Peak $\tan \delta$ & Storage modulus (GPa) & Loss modulus (MPa) \\
\hline \multirow[t]{8}{*}{ Capron 8202} & 0 & Dry & & 70.77 & 0.1254 & 1.835 & 0.0466 \\
\hline & After immersion & & & & & & \\
\hline & 720 & $25^{\circ} \mathrm{C}$ & Diesel & 53.10 & 0.1049 & 1.372 & 113.400 \\
\hline & 720 & $25^{\circ} \mathrm{C}$ & B20 & 46.65 & 0.1038 & 1.188 & 116.800 \\
\hline & 720 & $25^{\circ} \mathrm{C}$ & $\mathrm{B} 100$ & 32.90 & 0.1029 & 1.239 & 121.500 \\
\hline & $720($ stressed $)$ & $25^{\circ} \mathrm{C}$ & Diesel & 45.30 & 0.1142 & 1.377 & 130.460 \\
\hline & & & B20 & 32.05 & 0.1067 & 1.197 & 124.350 \\
\hline & & & $\mathrm{B} 100$ & 30.55 & 0.1099 & 1.078 & 116.540 \\
\hline \multirow[t]{8}{*}{ Capron 8351} & 0 & Dry & & 70.2 & 0.1303 & 1.314 & 0.0619 \\
\hline & After immersion & & & & & & \\
\hline & 720 & $25^{\circ} \mathrm{C}$ & Diesel & 56.40 & 0.1176 & 1.134 & 92.500 \\
\hline & 720 & $25^{\circ} \mathrm{C}$ & B20 & 57.35 & 0.1078 & 1.168 & 94.860 \\
\hline & 720 & $25^{\circ} \mathrm{C}$ & B100 & 56.10 & 0.1078 & 1.215 & 92.100 \\
\hline & $720($ stressed $)$ & $25^{\circ} \mathrm{C}$ & Diesel & 55.25 & 0.1235 & 0.967 & 91.703 \\
\hline & & & B20 & 56.15 & 0.1120 & 0.868 & 88.673 \\
\hline & & & B100 & 56.25 & 0.1102 & 0.773 & 78.912 \\
\hline
\end{tabular}

immersion are also given in Table 2. Each value in the table is an average of three specimens. It can be observed in Table 2 that Capron 8202 had higher strengths than Capron 8351. This is because Capron 8351 is a copolymer containing a randomly dispersed softer phase in the polyamide- 6 matrix.

All of the specimens tested in tension failed at locations away from the grips. Figure 5 shows photographs of the failed ends of dry Capron 8202 and 8351 specimens after tensile tests. Ductile failure of both materials tested before immersion and after 720-h immersion in B100 can be observed in this figure. Similar failure occurred after immersion in diesel and B20. Thus, immersion in all three fuels up to $720 \mathrm{~h}$ did not cause any changes in the failure mode. However, as can be seen in Table 2, both Capron 8202 and 8351 specimens experienced reductions in yield and tensile strengths after immersion. In general, reduction in yield strength was higher for specimens immersed under stress.

\section{Dynamic Mechanical Properties}

DMA provided the dynamic mechanical properties, such as tan $\delta$, storage modulus, and loss modulus plots as a function of temperature. From these plots, glass transition temperature $\left(T_{g}\right)$, peak $\tan \delta$, storage modulus at $25^{\circ} \mathrm{C}$, and loss modulus at $25^{\circ} \mathrm{C}$ were determined and compared between before immersion and after immersion specimens. Each experiment was conducted in triplicate; the averaged values are given in Table 3.

Figure 6 shows typical DMA diagrams obtained with Capron 8202 and Capron 8351 specimens before immersion. The peak of the $\tan \delta$ curve occurs at the glass transition temperature of the polymer. At this temperature, a large decrease in storage modulus is observed. For Capron 8202, which is a homopolymer, the experiment was conducted from approximately $30^{\circ} \mathrm{C}$ to $110^{\circ} \mathrm{C}$. As can be seen in Fig. 6a, there was a single tan $\delta$ peak, corresponding to the $T_{g}$ of polyamide- 6 at $72^{\circ} \mathrm{C}$. For the Capron 8351 specimen, which is a copolymer, the experiment was conducted from $-110^{\circ} \mathrm{C}$ (using liquid nitrogen) to $110^{\circ} \mathrm{C}$. In this case, two tan $\delta$ peaks were observed (Fig. 6b). The smaller peak at $-60.2^{\circ} \mathrm{C}$ corresponds to the soft rubbery phase in Capron 8351 and the larger peak at $70.2^{\circ} \mathrm{C}$ corresponds to the polyamide- 6 molecules. The larger peak is considered the primary glass transition temperature of Capron 8351.
Glass Transition Temperature $\left(\boldsymbol{T}_{g}\right)$. Figure 7 shows that $T_{g}$ of Capron 8202 and 8351 decreased with increasing immersion time in all three fuels. It can also be seen that for the same immersion
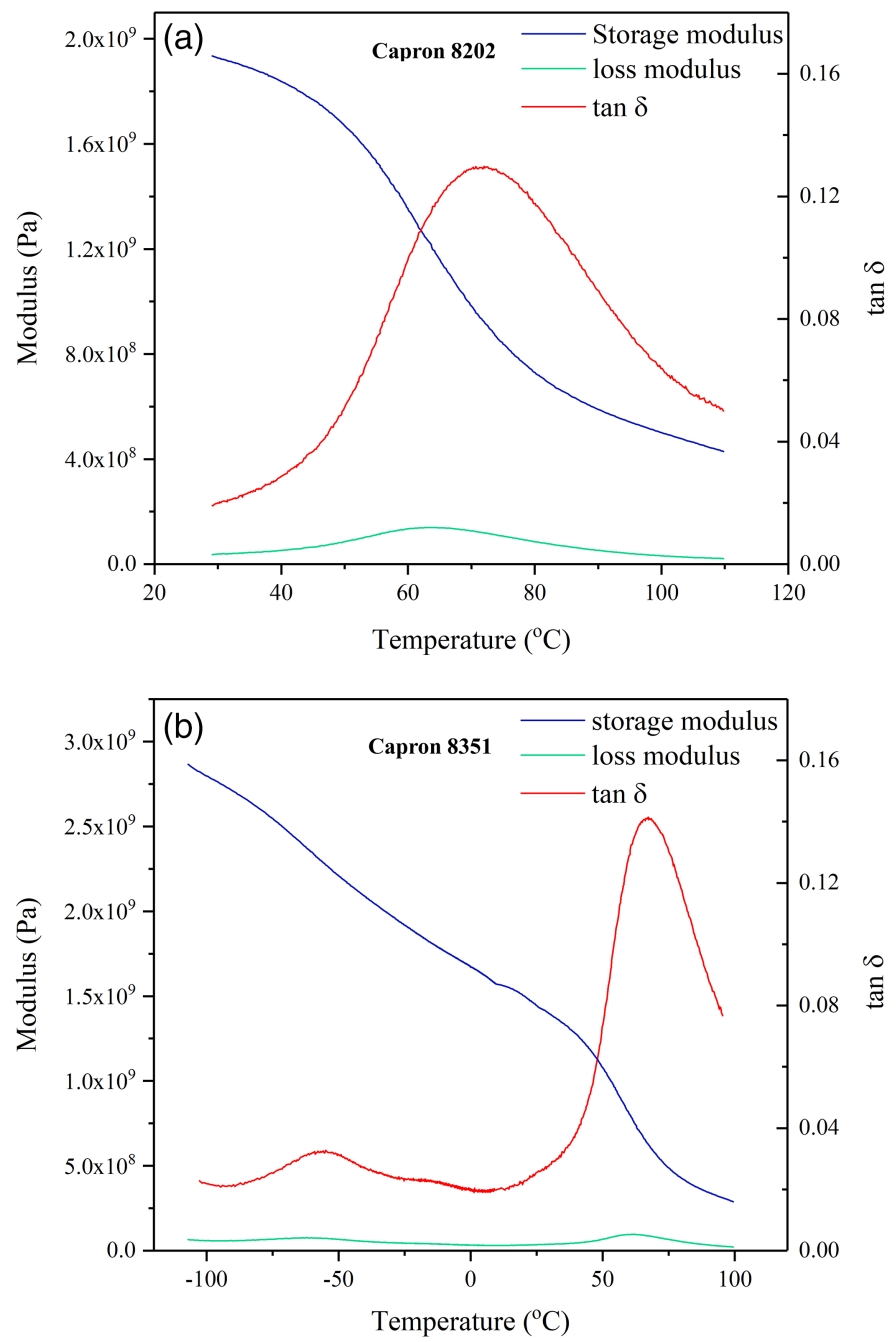

FIG. 6. DMA diagrams of (a) Capron 8202 and (b) Capron 8351, both before immersion. [Color figure can be viewed at wileyonlinelibrary.com] 

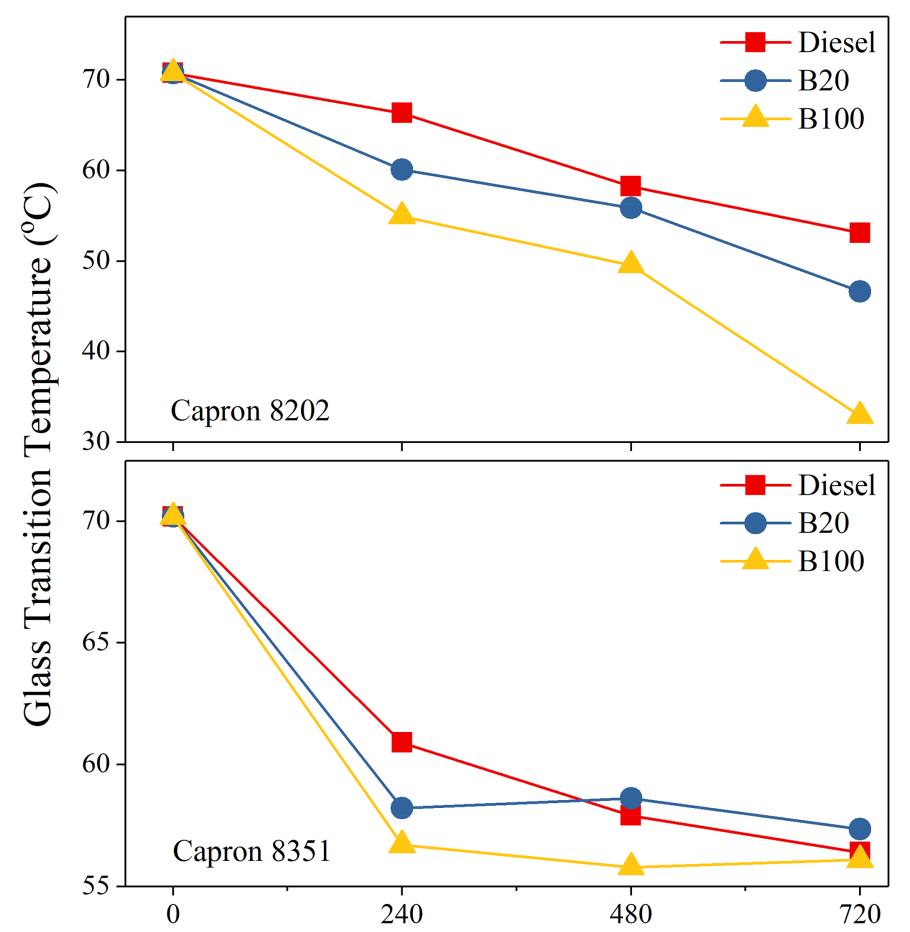

Immersion Time (Hour)

FIG. 7. Variation of glass transition temperatures of Capron 8202 and 8351 with immersion time. [Color figure can be viewed at wileyonlinelibrary.com]

time, $T_{g}$ of Capron 8202 decreased with increasing biodiesel content. Figure 7 shows that $T_{g}$ of Capron 8351 also decreased after $240 \mathrm{~h}$ of immersion; however, it appears to have leveled off at between $57^{\circ} \mathrm{C}$ and $58^{\circ} \mathrm{C}$.

Peak tan $\delta$. Figure 8 shows peak tan $\delta$ of Capron 8202 and Capron 8351 as a function of immersion time. It can be observed that peak $\tan \delta$ of Capron 8202 reduced significantly after immersion in all three fuels. However, changes in peak tan $\delta$ after $240 \mathrm{~h}$ of immersion were relatively small. The peak $\tan \delta$ of Capron 8351 also decreased significantly and its value became lower with increasing immersion time. It was also observed that the $\tan \delta$

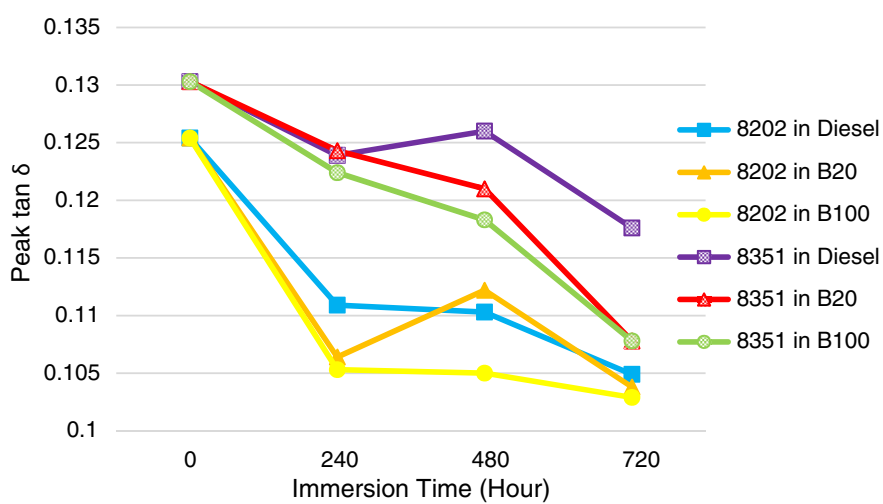

FIG. 8. Variation of peak tan $\delta$ of Capron 8202 and 8351 with immersion time. [Color figure can be viewed at wileyonlinelibrary.com]
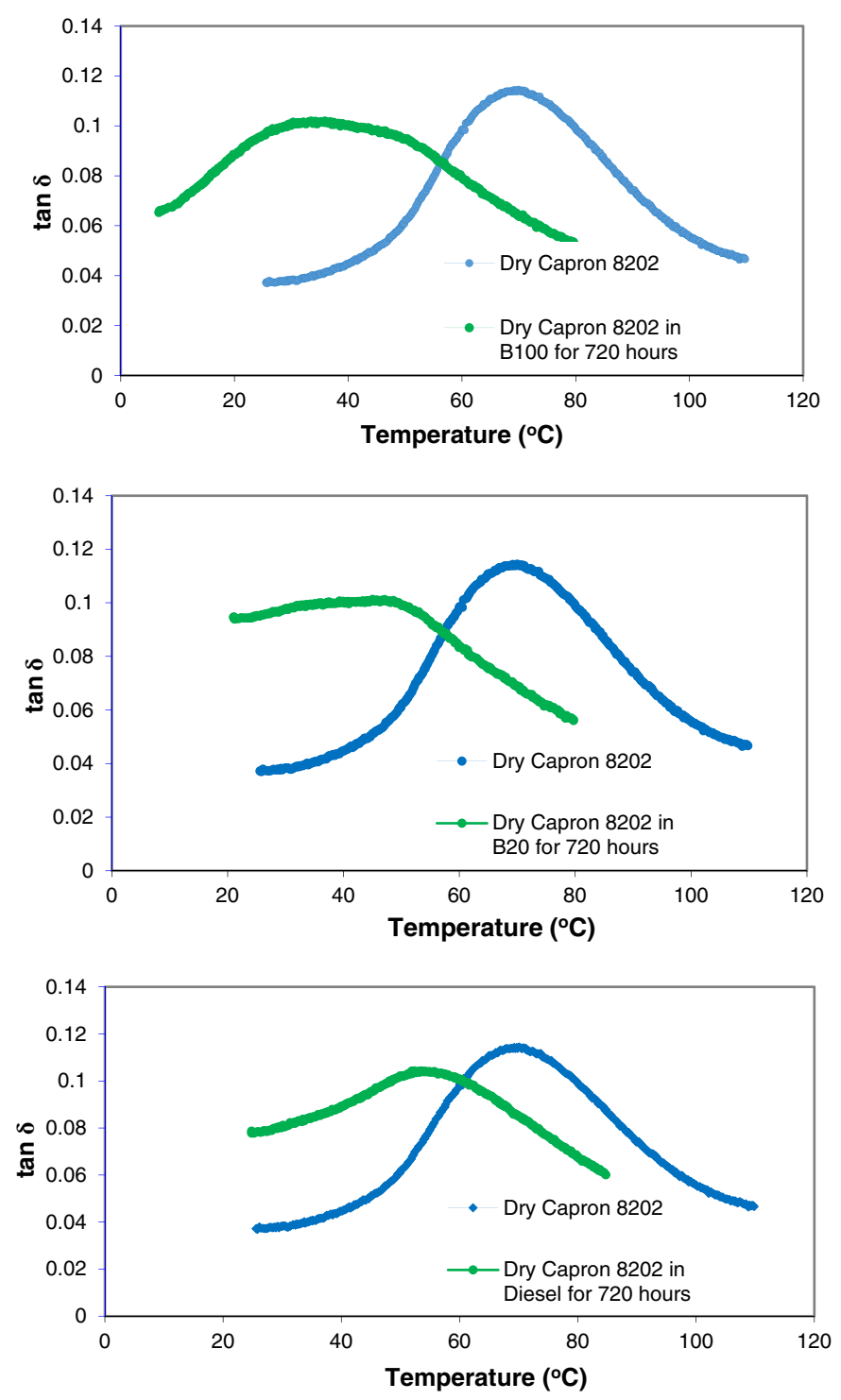

FIG. 9. $\tan \delta$ of Capron 8202 as a function of temperature before and after immersion in B100 (top), B20 (middle), and diesel (bottom) for $720 \mathrm{~h}$. [Color figure can be viewed at wileyonlinelibrary.com]

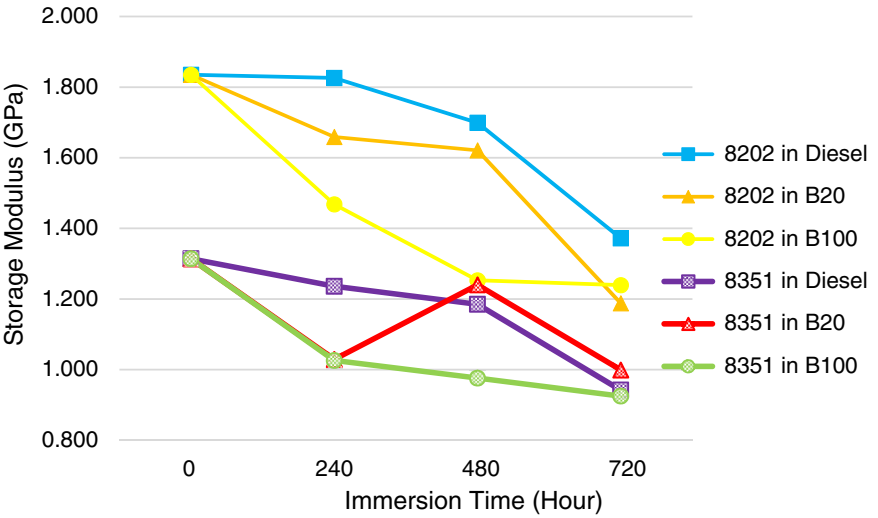

FIG. 10. Variation of storage moduli of Capron 8202 and 8351 with immersion time. [Color figure can be viewed at wileyonlinelibrary.com] 


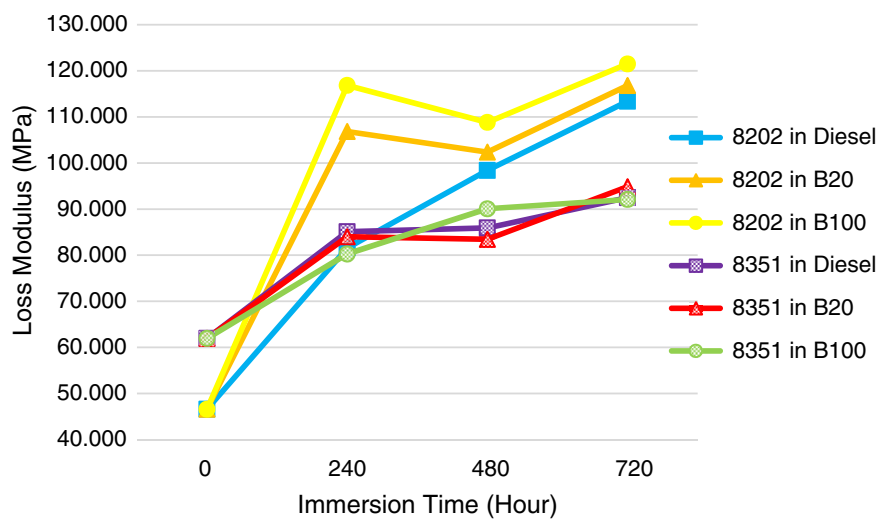

FIG. 11. Variation of loss moduli of Capron 8202 and 8351 with immersion time. [Color figure can be viewed at wileyonlinelibrary.com]

curve was broadened by the absorption all three fuels into both polymers. This is shown in Fig. 9 for Capron 8202.

Storage and Loss Moduli. Figure 10 shows the $25^{\circ} \mathrm{C}$ storage modulus of 8202 and 8351 specimens as a function of immersion time. For both polymers, storage modulus decreased with increasing immersion time. Figure 11 shows the loss modulus changes of Capron 8202 and Capron 8351 after $25^{\circ} \mathrm{C}$ immersion. For both polymers, the loss modulus increased with increasing immersion time.

\section{DSC Measurements}

Figure 12 shows the DSC thermograms obtained during heating and cooling stages for Capron 8202 and 8351 specimens before immersion and after 720-h immersion in B100. Similar thermograms were obtained before and after immersions in diesel and B20. From the heating thermograms, the primary crystalline melting peaks for Capron 8202 specimens are at $223.61^{\circ} \mathrm{C}$ before immersion and $224.49^{\circ} \mathrm{C}$ after immersion in B100. For Capron 8351 specimens, the primary crystalline melting peaks are at $221.63^{\circ} \mathrm{C}$ and $221.64^{\circ} \mathrm{C}$, respectively. In addition to the primary crystalline melting peak, there is an additional melting peak at $96.84^{\circ} \mathrm{C}$ for Capron 8351 before immersion and $95.65^{\circ} \mathrm{C}$ after immersion. These secondary melting peaks may be attributed to the melting of the soft phase in Capron 8351. No additional notable features were observed on DSC thermograms of either Capron
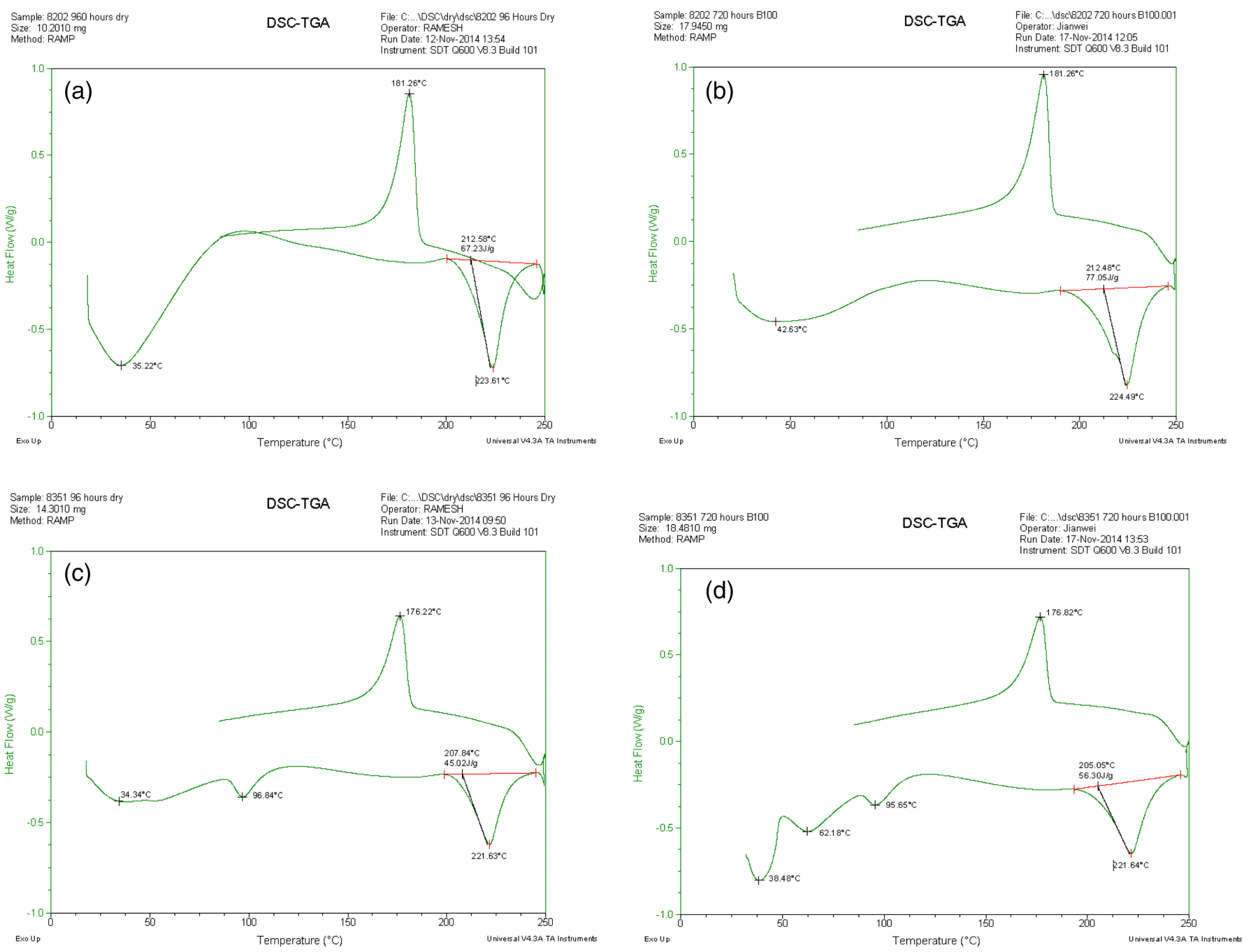

FIG. 12. DSC thermograms of Capron 8202 and 8351 specimens before and after immersion in B100 for $720 \mathrm{~h}$ :

(a) Capron 8202 before immersion, (b) Capron 8351 before immersion, (c) Capron 8202 after immersion, and

(d) Capron 8351 after immersion. [Color figure can be viewed at wileyonlinelibrary.com] 
TABLE 4. Degree of crystallinity and melting temperature of Capron 8202 and 8351 before and after 720 -h immersion at $25^{\circ} \mathrm{C}$.

\begin{tabular}{|c|c|c|c|c|c|c|}
\hline \multirow[b]{2}{*}{ Immersion time $(\mathrm{h})$} & \multirow{2}{*}{\multicolumn{2}{|c|}{ Immersion condition }} & \multicolumn{2}{|l|}{ Capron 8202} & \multicolumn{2}{|l|}{ Capron 8351} \\
\hline & & & $\%$ Crystallinity & $T_{m}\left({ }^{\circ} \mathrm{C}\right)$ & $\%$ Crystallinity & $T_{m}\left({ }^{\circ} \mathrm{C}\right)$ \\
\hline 0 & Before i & & 29.23 & 223.61 & 19.57 & 221.63 \\
\hline 720 & $25^{\circ} \mathrm{C}$ & Diesel & 31.5 & 225.99 & 19.93 & 221.02 \\
\hline 720 & $25^{\circ} \mathrm{C}$ & B20 & 36.17 & 223.98 & 18.99 & 221.28 \\
\hline 720 & $25^{\circ} \mathrm{C}$ & B100 & 33.49 & 224.49 & 24.47 & 221.64 \\
\hline \multirow[t]{3}{*}{720 (stressed) } & $25^{\circ} \mathrm{C}$ & Diesel & 31.13 & 224.12 & 20.28 & 221.64 \\
\hline & & B20 & 30.38 & 224.42 & 20.03 & 222.48 \\
\hline & & $\mathrm{B} 100$ & 33.85 & 223.97 & 19.01 & 220.06 \\
\hline
\end{tabular}

8202 or 8351 specimens that can be associated with the effect of immersion in any of the three fuels.

The DSC thermograms provided the information on the degree of crystallinity and the primary melting peak that are listed in Table 4. As can be observed in this table and also in Fig. 13, the degree of crystallinity of Capron 8202 was higher than that of Capron 8351. Although the changes in melting peak, $T_{m}$, were not significant for either polymer, the degree of crystallinity of both polymers increased slightly with increasing immersion time in all three fuels. However, the increase in the degree of crystallinity of Capron 8351 was much smaller.

\section{FTIR Spectra}

Figure 14 shows the FTIR spectra in absorbance mode for Capron 8202 and Capron 8351 specimens before and after immersions in diesel, B20, and B100 under different immersion conditions. All of the spectra show the IR absorbance peaks that are normally found for polyamide- 6 . A compilation of the observed peaks is given in Table 5 for Capron 8202 and Capron 8351, respectively. This table also lists the standard FTIR peaks that are used to identify the chemical structure of polyamide-6. By comparing the observed peaks with the standard peaks, it can be concluded that no discernible chemical changes occurred due to the absorption of fuels in the polymers.

\section{DISCUSSION}

The effect of fuel-polymer interactions can be divided into two main categories: physical interaction and chemical interaction, both occurring due to the diffusion and absorption of fuel

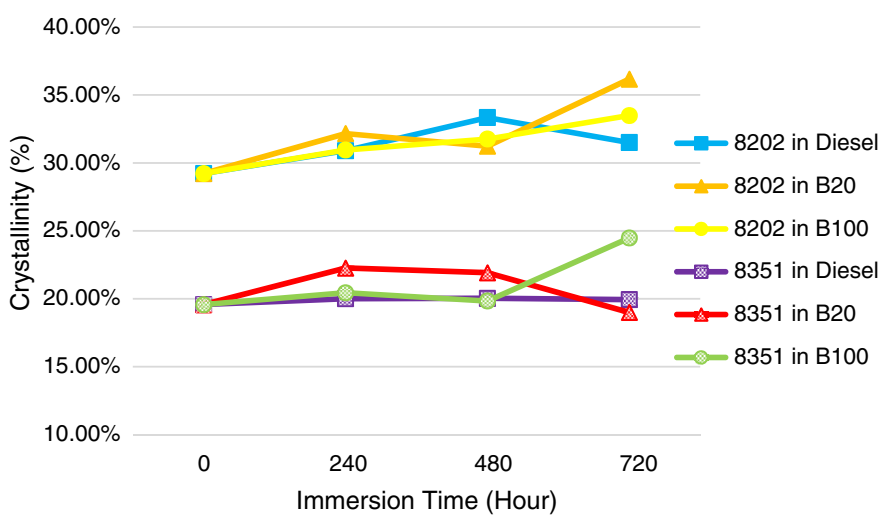

FIG. 13. Variation of degree of crystallinity of Capron 8202 and 8351 as a function of immersion time. [Color figure can be viewed at wileyonlinelibrary.com] into the polymer [1]. Since fuel molecules are much smaller than the polymer molecules, they may be absorbed in the polymer, and act as a plasticizer, altering its physical and mechanical properties,
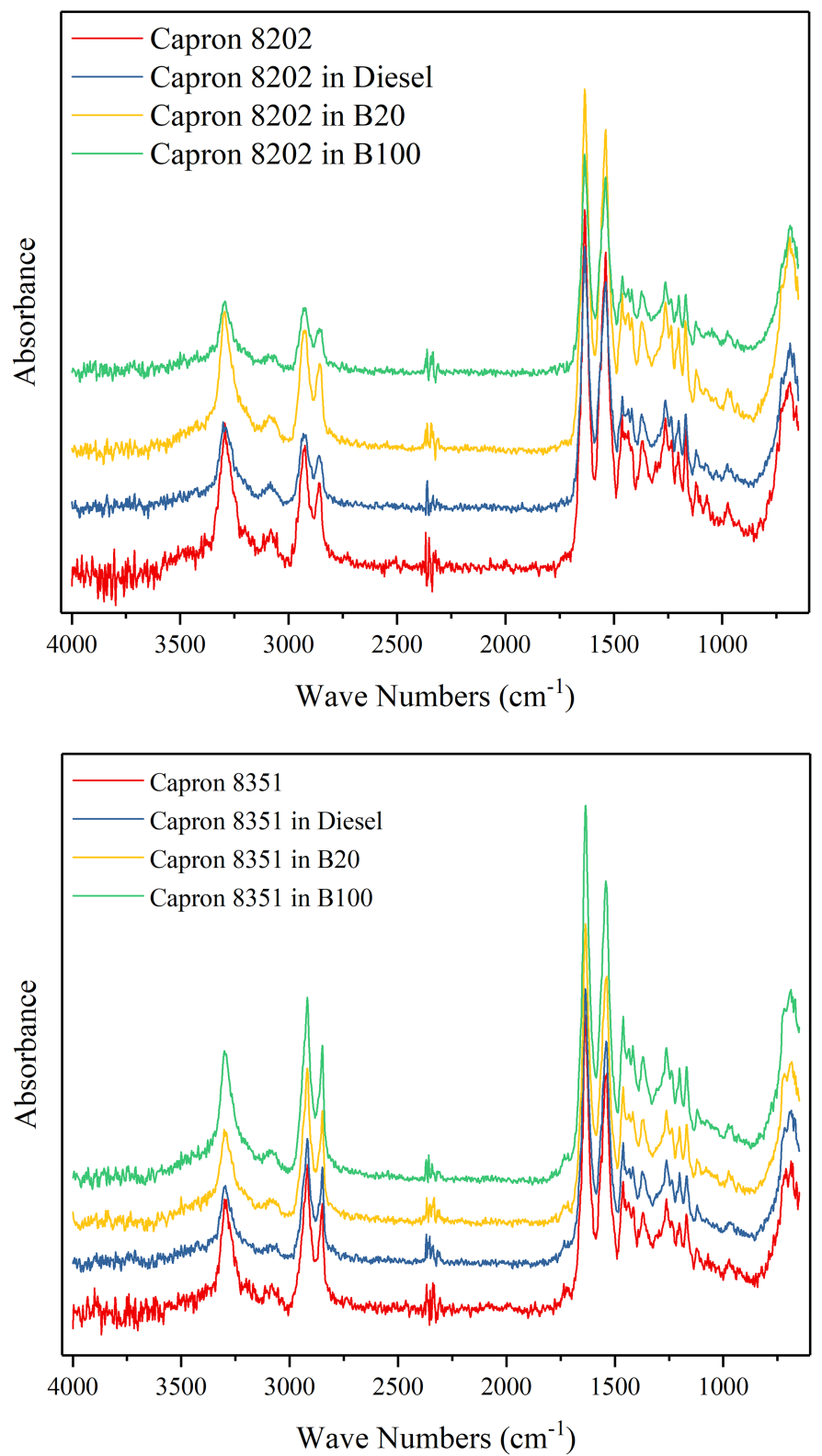

FIG. 14. FTIR absorbance spectra of Capron 8202 and 8351 before immersion and after 720-h immersion. [Color figure can be viewed at wileyonlinelibrary.com] 
TABLE 5. FTIR wave numbers observed for Capron 8202 and 8351 before and after 720 -h immersion at $25^{\circ} \mathrm{C}^{\mathrm{a}}$.

\begin{tabular}{|c|c|c|c|c|c|c|c|c|c|}
\hline \multirow[b]{2}{*}{$\begin{array}{l}\text { Standard wave } \\
\text { numbers }\left(\mathrm{cm}^{-1}\right)\end{array}$} & \multirow[b]{2}{*}{ Functional group } & \multicolumn{4}{|c|}{ Capron 8202} & \multicolumn{4}{|c|}{ Capron 8351} \\
\hline & & $\begin{array}{l}\text { Before } \\
\text { immersion }\end{array}$ & Diesel & B20 & B100 & $\begin{array}{l}\text { Before } \\
\text { immersion }\end{array}$ & Diesel & B20 & B100 \\
\hline 3,294 & $\mathrm{~N}-\mathrm{H}$ stretching & 3,294 & 3,302 & 3,295 & 3,294 & 3,300 & 3,295 & 3,300 & 3,300 \\
\hline 3,083 & $\mathrm{~N}-\mathrm{H}$ stretching & 3,084 & 3,083 & 3,089 & 3,094 & 3,082 & 3,085 & 3,085 & 3,085 \\
\hline 2,937 & Antisymmetric $\mathrm{CH}_{2}$ stretching & 2,924 & 2,932 & 2,924 & 2,922 & 2,918 & 2,919 & 2,918 & 2,918 \\
\hline 2,868 & Symmetric $\mathrm{CH}_{2}$ stretching & 2,860 & 2,859 & 2,856 & 2,857 & 2,850 & 2,850 & 2,850 & 2,850 \\
\hline 1,645 & $\mathrm{C}=\mathrm{O}$ stretching & 1,635 & 1,635 & 1,635 & 1,635 & 1,635 & 1,635 & 1,635 & 1,635 \\
\hline 1,545 & $\mathrm{C}-\mathrm{N}$ stretching & 1,536 & 1,536 & 1,536 & 1,536 & 1,537 & 1,541 & 1,541 & 1,541 \\
\hline 1,477 & $\mathrm{CH}_{2}$ scissor vibration & 1,462 & 1,460 & 1,460 & 1,460 & 1,460 & 1,460 & 1,460 & 1,461 \\
\hline 1,417 & $\mathrm{CH}_{2}$ scissor vibration & 1,432 & 1,417 & 1,417 & 1,417 & 1,417 & 1,417 & 1,417 & 1,417 \\
\hline 1,374 & $\mathrm{CH}_{2}$ wagging vibration & 1,370 & 1,370 & 1,370 & 1,370 & 1,370 & 1,374 & 1,374 & 1,370 \\
\hline 1,264 & $\mathrm{~N}-\mathrm{H}$ bending and $\mathrm{C}-\mathrm{N}$ stretching & 1,262 & 1,262 & 1,262 & 1,262 & 1,262 & 1,262 & 1,262 & 1,262 \\
\hline 1,201 & $\mathrm{CH}_{2}$ twist-wagging vibration & 1,202 & 1,201 & 1,202 & 1,202 & 1,202 & 1,202 & 1,202 & 1,202 \\
\hline 1,170 & $\mathrm{CO}-\mathrm{NH}$ skeletal motion & 1,168 & 1,168 & 1,168 & 1,168 & 1,168 & 1,168 & 1,168 & 1,168 \\
\hline 960 & $\mathrm{C}=\mathrm{O}$ and $\mathrm{N}-\mathrm{H}$ in-plane vibration & 975 & 975 & 975 & 975 & 975 & 975 & 975 & 975 \\
\hline 692 & $\mathrm{NH}$ out-of-plane bending & 690 & 688 & 688 & 688 & 686 & 685 & 685 & 686 \\
\hline
\end{tabular}

${ }^{\mathrm{a}}$ Immersion time $720 \mathrm{~h}$ at $25^{\circ} \mathrm{C}$.

such as modulus, toughness, and strength of the polymer. The direct contact between the fuel and the polymer may cause stress cracking on the polymer surface, which can accelerate fuel penetration into the polymer. Chemical interaction involves modification of polymer molecules. The most possible mechanism for chemical interaction is polymer oxidation, which may or may not accompany fuel oxidation. The existence of moisture in the polymer and the fuel may also cause hydrolysis of polymers that contain functional groups, such as esters, amides, and acetals, in their molecules. These functional groups can interact with water molecules to form acid or aldehyde groups. Since some biodiesels contain FAME with unsaturated bonds $(\mathrm{C}=\mathrm{C})$, polymer, and biodiesel may co-oxidize on direct contact. The reactions may be more active if the polymers also contain unsaturated carbon bonds. The rate of interaction depends on the sensitivity of the polymer to several influencing factors, including the composition of the polymer itself.

In our experiments, weight increase of both Capron 8202 and 8351 specimens clearly indicates that all three fuels were absorbed into the polymers. Tensile tests have shown that both yield and tensile strengths decreased after immersion in all three fuels. The DMA experiments have shown that there were significant decreases in the glass transition temperature and storage modulus. Peak tan $\delta$ and loss modulus, on the other hand, increased. There was also a broadening of the tan $\delta$ peak. DSC measurements indicated that there was a modest increase in crystallinity; however, the melting peak was not much affected. Finally, FTIR absorbance data indicated that the IR peaks did not shift and no new peaks appeared after immersion. Since there were no new peaks and all the peaks that were observed with unimmersed polymers also appeared in immersed polymers, it is concluded that no chemical changes occurred due to the absorption of any of the fuels.

Decrease in $T_{g}$ and broadening of $\tan \delta$ peaks after immersion indicate that the absorbed fuels are acting like a plasticizer. The small hydrocarbon molecules of diesel and fatty acid molecules of biodiesel diffuse between the polyamide molecules, thus reducing the strength of secondary bonding between them. Plasticizing effect is also evident when storage moduli of unimmersed and immersed polymers are compared. Reductions in yield and tensile strengths, although not as large as those of storage moduli, are also due to the plasticizing effect.

Anda et al. [26] observed decreases in glass transition temperature of P-66 after immersion in a series of polar, amphiphilic and nonpolar solvents. They attributed the decrease in glass transition temperature to alteration of molecular mobility due to breakage of interchain hydrogen bonds in the case of polar solvents and modification of hydrogen bonds through steric effects in the case of nonpolar solvents. Sfirakis and Rogers [27] conducted immersion experiments with polyamide- 6 in water, methanol, and ethanol, and observed that crystallinity of polyamide- 6 was not appreciably affected by the absorption of these three fluids. The properties of polyamide- 6 were reduced by their diffusion into the polymer. They concluded that the absorption mainly took place in the amorphous region and the mobility of the polymer molecules was reduced by their presence. Laurati et al. [28] observed that absorption of water and ethanol molecules in semicrystalline aromatic and aliphatic P-66-induced some reorganization of the hydrogen bonds in the crystalline phase, but also increased the mobility of the amorphous segments of the molecules in the interlamellar regions. Similar observations are summarized by Murthy [29] in his review article that addressed the effect of solvents on aliphatic polyamides, such as polyamide- 6 .

In the current study, the crystallinity was modestly affected by the absorption of all three fuels into both Capron 8202 and 8351 . The molecules of both diesel and biodiesel were perhaps also absorbed in the amorphous region, but their absorption has created a plasticizing effect which resulted in lowering of the glass transition temperature, storage modulus and strengths. Since the liquids used in this study are nonpolar, the plasticization effect may be attributed to the steric effects as suggested in Ref. 26.

\section{CONCLUSIONS}

This study investigated the effect of biodiesel on two polyamide6-based semicrystalline polymers, a homopolymer (Capron 8202) and a graft copolymer (Capron 8351) using immersion tests at $25^{\circ} \mathrm{C}$. In addition to biodiesel, the effects of diesel and a $20 / 80$ 
blend of diesel and biodiesel were also considered. Immersion of both polymers in all three fuels caused increase in weight due to absorption of fuels; however, the weight increase did not reach the equilibrium level in $720 \mathrm{~h}$. The weight increase was the highest in biodiesel and lowest in diesel under both stressed and unstressed conditions. Both yield and tensile strengths of Capron 8202 and 8351 decreased after immersion in all three fuels; however, the tensile failure mode remained ductile. The glass transition temperature, storage modulus, and peak $\tan \delta$ decreased and the loss modulus increased. The degree of crystallinity increased slightly, while the melting peak was not influenced much. No changes in the chemical structure were observed in the FTIR data.

Based on the experimental observations reported here, it is concluded that all three fuels acted as plasticizers in both polyamide6-based semicrystalline polymers investigated in this research, and it appears that there were no chemical degradation for up to $720 \mathrm{~h}$ of exposure at room temperature. In terms of aggressivity among the three fuels considered, the effect of biodiesel absorption appears to be slightly higher than diesel in both polymers.

\section{REFERENCES}

1. E. Richaud, F. Djouani, B. Fayyolle, J. Verdu, and B. Flaconneche, Oil Gas Sci. Technol., 70, 317 (2015).

2. S.K. Hoekman, A. Broch, C. Robbins, E. Ceniceros, and M. Natarajan, Renew. Sustain. Energ. Rev., 16(1), 143 (2012).

3. S.A. Basha, K.R. Gopal, and S. Jebaraj, Renew. Sustain. Energ. Rev., 13(6), 1628 (2009).

4. S. Pinzi, I.L. Garcia, F.J. Lopez-Gimenez, M.D. Luque de Castro, G. Dorado, and M.P. Dorado, Energy Fuels, 23(5), 2325 (2009).

5. A.E. Atabani, A.S. Silitonga, I.A. Badruddin, T.M.I. Mahlia, H. H. Masjuki, and S. Mekhilef, Renew. Sustain. Energ. Rev., 16(4), 2070 (2012).

6. A. Haseeb, M.A. Fazal, M.I. Jahirul, and H.H. Masjuki, Fuel, 90 (3), 922 (2011).

7. G.B. Besse and J.P. Fey, "Compatibility of Elastomers and Metals in Biodiesel Fuel Blends," SAE Technical Paper 971690 (1997).

8. A.S.M.A. Haseeb, H.H. Masjuki, C.T. Siang, and M.A. Fazal, Renew. Energ., 35, 2356 (2010).

9. A.S.M.A. Haseeb, T.S. Jun, M.A. Fazal, and H.H. Masjuki, Energy, 36, 1814 (2012).

10. S.M. Alves, V.S. Mello, and J.S. Medeiors, Tribol. Int., 65, 74 (2013).
11. B. Terry, R.L. McCormick, and M. Natarajan, "Impact of Biodiesel Blends on Fuel System Component Durability," SAE Technical Report 2006-01-3279 (2006).

12. E.W. Thomas, R.E. Fuller, and K. Terauchi, "Fluoroelastomer Compatibility with Biodiesel Fuels," SAE Technical Report 2007-01-4061 (2007).

13. T. Nakai and H. Ogishi, "Verification of Influences of Biodiesel Fuel on Automotive Fuel-Line Rubber and Plastic Materials," SAE Technical Report 2010-01-0915 (2010).

14. E. Richaud, B. Flaconnèche, and J. Verdu, Polym. Test., 31(8), 1070 (2012).

15. M. Böhning, U. Niebergall, A. Adam, and W. Stark, Polym. Test., 34, 17 (2014).

16. M. Böhning, U. Niebergall, A. Adam, and W. Stark, Polym. Test., 40, 133 (2014).

17. M. Böhning, U. Niebergall, M. Zanotto, and V. Wachtendorf, Polym. Test., 50, 315 (2016).

18. G. Lutz and J.F. Mata-Segreda, J. Phys. Org. Chem., 21, 1068 (2008).

19. K. Ullah, "Aging of Polymer in Diesel and Biodiesel Blended Fuel," Master's Thesis, Chalmers University of Technology, Goteborg, Sweden (2013).

20. B. Baleno, E. Benjamin, K. Desai, L. Norfolk, and A. Carvalho, "Design Considerations for High-Performance Polymers Used in Biofuel Components," SAE Technical Report 2011-36-0021 (2011).

21. M. Gomej-Mares, M.E. Martinez-Ortega, G. Arroyo-Ortega, H. Reyes-Blas, J. Hernandez-Paz, and C. Marquez-Marquez, J. Mater. Sci. Eng., 3, 142 (2014). https://doi.org/10.4172/21690022.1000142.

22. L.M. Baena, E.C. Zuleta, and J.A. Calderón, Polymers, 10, 511 (2018).

23. http://www.matweb.com/search/datasheetText.aspx ?bassnum= PALC21, BASF Capron 8202 Nylon-6

24. http://www.matweb.com/search/datasheettext.aspx ?matguid=8b59 b3a432504220ae283074405b309f, BASF Capron 8351 impact modified Nylon-6.

25. A.W. Birley, B. Haworth, and J. Batchelor, Physics of Plastics, Hanser Publishers, Munich, Germany (1991).

26. A.R. de Anda, L.A. Fillot, S. Rossi, D. Long, and P. Sotta, Polym. Eng. Sci., 51, 2129 (2011).

27. A. Sfirakis and C.E. Rogers, Polym. Eng. Sci., 20(4), 294 (1980).

28. M. Laurati, A. Arbe, A.R. de Anda, L.A. Fillot, and P. Sotta, Polymer, 55, 2867 (2014).

29. N.S. Murthy, J. Polym. Sci. Part B: Polym. Phys., 44, 1763 (2006). 